Illinois State University

ISU ReD: Research and eData

Winter 2019

\title{
Digging Up the Past: Archival Issues with Found Time Capsules at Illinois State University
}

April K. Anderson-Zorn

Illinois State University, aander2@ilstu.edu

Follow this and additional works at: https://ir.library.illinoisstate.edu/fpml

Part of the Archival Science Commons

\section{Recommended Citation}

Anderson-Zorn, April K., "Digging Up the Past: Archival Issues with Found Time Capsules at Illinois State University" (2019). Faculty and Staff Publications - Milner Library. 126.

https://ir.library.illinoisstate.edu/fpml/126

This Article is brought to you for free and open access by the Milner Library at ISU ReD: Research and eData. It has been accepted for inclusion in Faculty and Staff Publications - Milner Library by an authorized administrator of ISU ReD: Research and eData. For more information, please contact ISUReD@ilstu.edu. 


\title{
Digging Up the Past: Archival Issues with Found Time Capsules at Illinois State University
}

\author{
April Karlene Anderson-Zorn
}

\begin{abstract}
During the demolition of an Illinois State University dormitory in the spring of 2016, workers discovered two time capsules. Tasked with their care, the university archivist looked for archival guidance on the safe handling of time capsules, best practices for working with their contents while balancing public demand for access. This case study examines the time capsule as an object of collective memory, how it fits into an institutional collection, the archivist's work to document and recover materials in two recently discovered time capsules, and how to work with multiple institutional departments to make them accessible. It suggests best practices for time capsule discoveries and outreach.
\end{abstract}

(C) April Karlene Anderson-Zorn. (cc) BY-NC

\section{KEY WORDS}

Advocacy, Collective memory, Collaboration,

College and university archives, Outreach 
$\mathrm{W}$

hen imagining a time capsule, one may picture a rusty metal box or cylinder full of objects from a long-ago era. Stuffed animals, books, coins, photographs, stamps, and other cultural artifacts chosen by one generation may be enclosed to tell their story to a future generation. Historians have coined various terms for these containers based on their contents and location, including "time vessel" and "time bomb." This case study will use the term "time capsule"-defined as "a container holding historical records or objects representative of current culture that is deposited (as in a cornerstone) for preservation until discovery by some future age."

In many ways, a time capsule is like a scrapbook. By way of ephemera and memorabilia, the collected materials tell the story of a moment in time. Regardless of age, time capsules have a "cool" factor that can excite a community. Generations can connect as parents and grandparents have a physical representation of their past to show to children and grandchildren. For those connected to the time capsule's contents, the materials are both a physical and emotional connection to the past. As was the case for one of the two time capsules discovered at Illinois State University (ISU) in 2016, the container used can fail, damaging or destroying its contents. Even damaged, time capsules are of value to archives as they foster communication with the community on archival advocacy and preservation of all archival materials.

While some articles discuss the use of time capsules in the discourse of public memory, they generally do not address how an archives should manage both the care of and access to the sometimes intellectually tricky and physically delicate materials they contain. In the case of the ISU time capsules, even damaged, the community felt protective of the materials, viewing them as an intrinsic part of their collective memory. Many alumni of the institution consider a water-damaged toy dog as valuable, not for what it is but for the emotional connection they perceive it to have to a now-lost physical space where they created cherished memories.

This case study will examine these cultural artifacts as objects in community memory and how collecting time capsules at an academic institution can enrich the often unrepresented areas of student life. I will also describe my work with multiple campus constituencies not only to recover and make accessible the time capsules, but also to help shift the community narrative from one of loss to one of cherished collective memories of a now-demolished residential space.

\section{Time Capsules as Cultural Artifacts and Collective Memory}

In his research on time capsules, historian Nick Yablon argues that they trace their roots to Gilded Age class and labor unrest. Yablon uses the phrase 
"time vessel," as most containers were deposited above ground in metal boxes, chests, and bank safes rather than being buried. Time vessels were used by the business elite to preserve their history when paper decay and the misinterpretation of monuments could potentially alter or destroy their version of history. The first manufactured time vessel made its debut in 1876 at the Philadelphia Centennial Exposition. Publisher Anna Deihm displayed her Century Safe, a large metal box resembling a bank vault. Inside the velvet-lined case were glass display areas meant not only to protect their historic contents but to show off the case as "as an advertising tie-in for its American manufacturer, the Marvin Safe Company." Yablon argues that the bourgeois elite used time vessels to store their history. In Yablon's view, “The time vessel was a cultural hybrid: a product both of new techniques for secreting precious objects developed by banks and archival preservationists and of a culture of exhibition then emerging out of department stores, museums, and world's fairs."

In the book Time Capsules: A Culture History, librarian William E. Jarvis examines the history of time capsules and the significance modern society places on them. Like Yablon, Jarvis looked at various time vault and capsule projects since the Philadelphia Centennial Exposition time vessel in 1876. Jarvis explains that the term "time capsule" is a recent phrase coined at the 1936 World's Fair at an exhibit for the Westinghouse Company. ${ }^{3}$ The plan was to bury a "time bomb," a vessel stuffed with cultural artifacts and to be unearthed in 5,000 years. A suggestion of the less aggressive "time capsule" was made and stuck. In an interview with the Long Now Foundation in 2005, Jarvis recounted how visitors reacted to the capsule's burial saying, "When that time capsule was formally lowered into the earth in 1938, an announcer intoned, 'Now it begins its long journey through time,' and people spontaneously took off their hats and bowed their heads while Taps was played."

Jarvis also describes one of the most ambitious time capsule projects in modern history: the Oglethorpe University time capsule, the Crypt of Civilization. Conceived in 1936 by then-university president Dr. Thornwell Jacobs and sealed in 1940, the crypt contains 2,000 cubic feet of cultural heritage and history including microfilmed copies of over 200 books; audio records; household goods such as electric razors, kitchen utensils, and children's toys; and "an apparatus for teaching the English language in case it is no longer spoken." The crypt is to be opened on May 28, 8113.

Like the Crypt of Civilization, creating a modern time capsule usually involves a group of individuals all working to preserve a moment in time for their community. In examining the concept of collective memory, Randall C. Jimerson points to scholarship that suggests that the human idea of having enough facts to create a narrative of past events may be flawed and that "Memory, history, and evidence interact and conflict in complex and fascinating ways." ${ }^{6}$ The 
collective memories of communities contribute to "shaping the self-identity" of these groups, memorializing stories of their pasts. Thus, "By enshrining certain events and experiences as part of a common history it embodies values, rituals, and directions for future actions."

In arguably his best-known work, La Mémoire collective, philosopher and sociologist Maurice Halbwachs theorizes that an individual's memory of an event can be part of a group's memory or "collective memory.” A group creates collective memory when it shares an event or a similar set of circumstances and passes that data among the group. "From the moment when we and these other witnesses belong to the same group and think in common about these matters, we maintain contact with this group and remain capable of identifying ourselves with it and merging our paths with its." Halbwachs describes a student who visits a former professor. The student relates class stories, discusses individual students, and recalls class events. However, as the class ended long ago, the professor has little memory of these events. Halbwachs explains that, for the students, the class was a shared experience. They were all likely similar in age, were part of similar social circles, and experienced the subject matter for the first time with the professor. The professor's class created a lasting memory for the students, one to which they could all relate. For the professor, the act of teaching the subject was a repetitive function. He remembered the students' faces and names, stories, and events during that teaching period. Once the class was over, the professor moved on to another class, and memories of his former students faded. Halbwachs suggests, "To be aided by others memory, ours must not merely be provided testimony and evidence but must also remain in harmony with theirs." Halbwachs further explains that collective memories exist through "shared data" because this information can pass between the individual mind and collective minds. Thus, "While the collective memory endures and draws strength from its base in a coherent body of people, it is individuals as group members who remember." ${ }^{10}$

Historic memory can also be collective memory, as groups of varying sizes can all play parts in an individual's life. Groups may retain their history "as a faithful resume of the most important events that have changed the life" of those groups. ${ }^{11}$ However, as the generations to which those histories pertain die, so do the collective memories of those groups. While those memories may have faded, historians search group histories to weave remaining memories into current society. As Halbwachs states, "Despite the variety of times and places, history reduces events to seemingly comparable terms, allowing their interrelation as variations on one or several themes." In this way, it gives "us a summary vision of the past, gathering into a moment and symbolizing in a few abrupt changes or in certain stages undergone by a people or individual, a slow collective evolution." ${ }^{2}$ 
Kenneth Foote argues that, along with oral and written tradition, archives help sustain community memory by transferring information from one generation to the next. Historians can create new interpretations of historic events from records to make connections in the current generation. Foote cites the Chicago Fire of 1871 and how it once was a dark footnote in the city's history but has in later years been turned into a narrative of community resilience. Foote also points to how the community of Salem, Massachusetts, uses the history of the Salem witch trials in its modern tourism. While the community acknowledges the trials (and even has a gift shop), the exact whereabouts of the executions of convicted witches is unknown. ${ }^{13}$

For archival and special collection repositories, the act of collecting materials makes archivists part of the "conscious act of memorializing some thing by the giving, receiving, and keeping of documentary records." ${ }^{14}$ Archivists save materials for a community that future generations will largely not have experience with, thus only ever knowing those materials' cultural history through written text or other media. ${ }^{15}$ Given that, the time capsules that the community creates and that archivists collect are designed with a narrow viewpoint and goal-to show future generations the social experience of the time. In the case of the Illinois State University time capsules, materials mostly represent the student experience-dance booklets, student newspapers and yearbooks, photographs of students and campus, and stuffed animals, among other pieces of student-made and student-focused ephemera. These items speak to the socialization of the university student, something Helen Willa Samuels deems an important part of the college student experience, stating that the practical lesson may not be as important as "the ability to learn and function in society." 16 While campus administrators are often the creators of items related to the student experience, Samuels points to the student-made ephemeral materials that most represent student socialization on campus. These materials describe the "informal contact" between students and the varied emotions that they experienced during their time at the institution. Student-made ephemeral materials can summon feelings and emotions from alumni, reconnecting the observer to a defining period in life, as "Each student need only reflect on his or her own academic career to recall the perils and rewards of these encounters." ${ }^{17}$

As the repository for Illinois State University's institutional memory, collecting student experience materials as well as connecting with community time capsule creators and researchers makes the Rayfield Archives an integral part of our community's public memory. In 2012, a survey conducted by Ellen Swain and Christopher Prom asked academic archivists about their holdings of student cultural records. In the survey, archivists agreed that while they wanted to collect materials related to the cultural activities of their student groups, they often found themselves hindered by a lack of resources. In her review 
of the survey, Jessica Wagner argues that academic archivists should focus on student life records, because "student life materials provide a unique window into the cultural expression of a group and an era, including documentation of taste, style, trends, politics, and attitudes about society that may not be as easily and honestly documented elsewhere." ${ }^{18}$ Time capsules, when considered records of cultural memory, do exactly that-document a microcosmic view into a specific era of a community's cultural memory.

However, it should be noted that time capsules contain materials collected by a community wishing to transmit a specific viewpoint. One community's memory of an event may not wholly represent that event. Time capsule materials may not include documents or cultural items important to an underrepresented or undocumented portion of that community. The 1995 Smithsonian display of the history of the Enola Gay serves as an example of a community interpreting its history differently than the institution did. The Smithsonian sought to educate its audience on an event that defined a generation and changed global politics forever. However, politicians, social commentators, and veterans groups all decried the exhibit as dishonoring the American military by questioning the use of the atomic bomb. Regardless of the Smithsonian's interpretation of the use of the bomb to end the war, veterans who visited the exhibit felt strongly that using the bomb saved thousands of American lives. In the end, collective memory won, and the director of the Smithsonian bowed to political pressure and closed the exhibit. ${ }^{19}$

Understanding the emotional connection a community has to its physical history can help archivists better care for these materials. As a time capsule is usually recovered when a structure is demolished, the community can see it as the remaining physical connection to that space and moment in time. Public historian Dolores Hayden believes that public memory and urban landscape are intrinsically tied together. A person's emotions can be deeply connected to a physical space. In that emotional connection lies one's own identity, shaped and defined by experiences in that space: "Identity is intimately tied to memory: both our personal memories (where we have come from and where we have dwelt) and the collective or social memories interconnected with the histories of our families, neighbors, fellow workers, and ethnic communities." 20 Thus, massive alteration or destruction of that physical space can cause distress in an individual. Hayden further states, "An individual's sense of place is both a biological response to the surrounding physical environment and a cultural creation." 21 With this in mind, one can see how former residents of a dormitory complex can be protective of both a deteriorating building and a copper box full of documents and artifacts. 


\section{Time Capsules Discovered}

After World War II, campuses nationwide saw an increase in their student populations. Veterans were returning to school in record numbers due to government-funded benefits that included free tuition. At ISU, then known as Illinois State Normal University, the increased student population put a strain on campus residential services. By the mid-1950s, the need for more student living space led to the development of a large, four-hall dormitory complex known as South Campus. Three other dormitory complexes were built over the next ten years, including one of the tallest dormitories in the country, Watterson Towers. However, South Campus remained the first of its generation, serving an average of 800 students in each wing, totaling 1,600 each term. As the university changed, dropping "Normal" from its name in 1964, so did its students. Classes that included the children and grandchildren of university alumni lived in the same residence halls as their parents and grandparents had. The university looked at renovating the South Campus complex but ultimately decided the project was cost prohibitive. When it was announced in 2011 that South Campus would be closed and demolished, many in the ISU community voiced sadness and frustration.

During the demolition, the campus's University Marketing and Communications (UMC) Department worked with the Dr. Jo Ann Rayfield Archives $^{22}$ to highlight the history of the buildings. While prepping the northside hall for demolition, a construction worker tasked with removing the cornerstone discovered a metal box. The site supervisor working for the university's Facilities Department contacted me, asking if the Rayfield Archives would be interested in having the capsule. I accepted and immediately contacted the Preservation unit in my library as well as UMC. We discussed a few ideas, including a press release on the capsule's discovery that would appear on the university's flagship news site and be posted to the university's social media accounts. UMC also wanted to try a new feature called Facebook Live, a service that Facebook introduced the previous year. The idea was intriguing; opening the time capsule live on social media would give viewers a chance to experience the history of their beloved building while, at the same time, promoting the work of the Rayfield Archives. As discussions progressed between the Rayfield Archives and UMC, questions arose about the time capsule's stability. From the outside, the metal box showed signs of possible water damage and corrosion. As one staff member joked, "Remember what happened to Geraldo Rivera!" He was referring to the 1986 live two-hour television special The Mystery of Al Capone's Vault, hosted by Rivera that revealed an empty vault. We decided that the Rayfield Archives would film the opening of the capsule, and, if the contents were intact, the film would be uploaded to the university's social media platforms. If the 
video generated enough interest, we would plan a separate live event that re-created the opening.

When the capsule arrived at the Rayfield Archives, I documented the object by taking notes and pictures of the weathered box. I measured the box at fourteen inches long, five and a quarter inches wide, and ten and a half inches high and noted that it had turned green from corrosion, an indicator of moisture in the cornerstone. It had a stick-welded seal around its top edge. I also observed that the box seemed much heavier than it should for a copper box presumably full of paper materials. The dense box worried me; holding the box upright with a slight tilt from each side yielded no movement of its contents. This indicated to me that the materials were either packed tightly in the box or that the box sustained a breach and was water damaged. I asked for our university Facilities Department to send over a carpenter who could use an angle grinder to cut through the welded thread on the box's lid. I expressed my concern about the contents, so those present stood back from the box as the lid was cut off. Knowing the contents could be damaged, the carpenter was careful to cut only the weld. Once we removed the lid, I could see wet paper materials, some of them with what appeared to be mold. Along with the head of Preservation, we donned paper masks, plastic aprons, and plastic gloves and moved the box to an outdoor location. It was a bright spring day, which was perfect for laying out a tarp next to our building, where we carefully removed materials from the wet box. Some paper materials were stuck together; rather than risk damaging them by forcing them apart, we left them to dry so that we could try separating them later. We were able to remove most materials individually.

Once we removed all of the materials from the box, we photographed each item and took an inventory. We then transferred the materials to a secure, well-ventilated indoor location at the Rayfield Archives to dry. The humidity in that area of the Rayfield Archives building is low, which helped dry the materials and mitigate any additional mold growth. Once dry, some materials required vacuuming of dormant mold spores. After we stabilized the time capsule materials, we salvaged approximately 75 percent of the box's contents. These materials included photographic prints and slides, pamphlets, dance booklets, residence hall rules and regulations, and a toy dog given as a dance memento. The remaining materials consisted of catalogs and other informational guides published by the university. While we could identify them based on their covers, the guides were waterlogged and mushy. Most pages stuck together, making the guides unusable. Because these items all had representative copies in other Rayfield Archives collections, we decided to document and discard these materials.

Because the materials needed immediate attention at the time of opening, UMC decided against a Facebook Live event. Instead, a short video of the initial 
opening was posted to the university's YouTube channel while social media posts from the Rayfield Archives, the university, and the university's main library informed followers of the discovery of a time capsule. Within twenty-four hours, several local news outlets contacted the Rayfield Archives requesting on-camera and radio interviews about the time capsule's discovery. UMC also wrote articles about the capsule, highlighting the materials found as mementoes of a bygone era. The narrative of a beloved residential complex being torn down had changed to one of nostalgia for a treasured space and the work to save damaged pieces of its history.

Within days of the time capsule's opening, I received calls from former South Campus residents that a second time capsule would be found in the adjacent, soon-to-be-demolished dormitory. After I informed administrators, Facilities, and UMC, we set up a time for the removal of the second time capsule. This time, the university photographer would be on hand to document the "discovery" of the time capsule and the transfer of the box to my care. Given the previous capsule's contents, I was concerned about a potential breach in the box's seal. However, this box was much lighter than the first, and I could feel materials shifting when I tilted it slightly. Bolstered by the prospect of an undamaged time capsule, Preservation, the Rayfield Archives, and UMC decided that this box might work for a Facebook Live event. Preservation and the Rayfield Archives still took precautions against possible mold or contaminants and removed the lid before the start of filming. After a quick look, the lid was loosely replaced, and the "opening" of the box was filmed live on the university's Facebook page. As of August 16, 2018, the video had over 12,000 views. ${ }^{23}$ Once again, local media outlets contacted the Rayfield Archives for interview requests, this time to highlight the story of two time capsule discoveries in one month.

In all, the discovery of the time capsules and their media focus lasted just over two months. In that time, capsule materials were temporarily housed in acid-free folders and boxes and inventoried in-house so that materials requested by the media could be easily accessed. Once media attention waned, we processed the capsules as individual collections and added them to a larger record group encompassing campus buildings and grounds. This experience also prompted me to question the whereabouts of other time capsules on campus. The Rayfield Archives staff identified nine buildings that are confirmed or strongly suspected to have time capsules in cornerstones or other locations. Along with this research, I created a protocols worksheet that the Rayfield Archives staff can use for future time capsule discoveries (see Appendix A). Using our experiences with the first two time capsule discoveries, I created a step-by-step checklist for working with materials from the point of time capsule discovery to the time it is processed and placed with the Rayfield Archives collections. This check-sheet 
is considered a live document that Rayfield Archives staff can update as we encounter time capsules created within the last fifty years. For example, we discovered that the Student Recreation Center, a newer building completed in 2010, has a time capsule created by students and enclosed in the outdoor cornerstone. It reportedly includes an iPod and a USB drive that contain files. We will need to update our protocols to take into consideration items that contain digital files-will we have the hardware and software necessary to access these materials? Will media on these devices even be recoverable after spending time encased and potentially exposed to midwestern weather? Researching potential time capsules and their years of placement will help us better prepare for their eventual return to the community.

\section{Developing Our Protocol}

The protocols developed at the Rayfield Archives for working with time capsules developed out of a fast-moving event. When we discovered the first capsule, we did not have any knowledge or background in working with time capsules. While quick reference searches yielded few results, four pamphlets later emerged that specifically discussed creating and working with time capsules. Most of the resources gave helpful suggestions for future time capsule handling. However, some recommendations would not fit within our repository's parameters.

The Smithsonian's Museum Conservation Institute (MCI) offers helpful suggestions for those creating a time capsule. ${ }^{24}$ The website includes information on metals that can be used, how to safely seal it, recommended materials for inclusion in a capsule, and ideal placement. The MCI also offers a list of hyperlinks to companies that specialize in time capsule creation. While the website does not advise how to work with found time capsules, it does provide a reference list that includes pamphlets that discuss best practices.

The Candian Conservation Institute's (CCI) pamphlet heavily focuses on time capsule creation. However, it does give recommendations on capsule recovery. When opening a time capsule, one must prepare for anything: "There is no simple way for determining the exact nature of the contents of metal boxes without opening them." 25 Acidic or volatile materials can become more so in an enclosed environment. When opening a capsule, "Avoid the very common practice of shaking the container, and keep the orientation of the capsule as it was when found." ${ }^{26}$ Unfortunately, this could not be avoided in our situation. Workers contracted by Facilities had initial contact with the South Campus capsules, and I could not speak directly with them to suggest best removal practices. The pamphlet also suggests resting the capsule on a quarter-inch dowel rod to determine even distribution of contents. To do this test, even if 
the box were in the proper orientation upon delivery, it would have meant a ninety-degree change to that orientation. For us, a slight tilt test of the first box was a useful compromise.

The South Carolina Department of Archives and History (SCDAH) offers a time capsule pamphlet similar to the CCI's. It makes similar recommendations; however, suggestions such as using a fiber optic camera to view the location of materials in an unopened box are impractical for small repositories and historical societies. The pamphlet does suggest researching the history of the placement of the time capsule: "A search of the local newspapers of the era may reveal not just the whereabouts of the cornerstone but also its construction and its contents." ${ }^{27}$ After the discovery of the South Campus time capsules, the Rayfield Archives staff created a list of current or suspected time capsules, complete with notes as to their approximate locations in buildings, the types of capsules, and possible contents. We will check future capsules against this list, and capsules not listed will be added and researched.

The creation of time capsules is also the focus in Helen Fraser's technical leaflet "The Time Capsule: Repository of the Past or Romantic Notion." While focused on capsule creation, Fraser offers a brief summary on opening a time capsule: "Take along equipment such as plastic gloves for protection against bacteria or chemicals, large blotters, glass for flattening warped or wet papers, spray bottles, a camera, and tools such as a hacksaw and pliers in case a metal box must be opened." ${ }^{28}$ Though her suggestions are brief, they are similar to the Rayfield Archives time capsule protocols.

"Protocols for Found Time Capsules" at the Rayfield Archives is a living document. As we recover capsules, our protocols will likely evolve. While these resources offer useful advice, we must adapt their recommendations to our specific needs. As we will likely never be present to remove a capsule ourselves, we can make recommendations for their safe removal. The resources scarcely discussed where to open a capsule. Given that our first capsule was water damaged and moldy, we made sure to open it in a well-ventilated area wearing masks, aprons, and gloves. However, the discussions about removing materials from capsules and researching capsule histories were useful. Moreover, as our time capsule discoveries showed, the removal and opening processes necessitate the involvement of other campus units. Including contact points for those units in our protocols will help smooth the recovery and access of future capsules for everyone.

Institutions can prepare now for their eventual time capsule discoveries. They can create checklists to their facilities' environments, personnel, and needs. Archivists can research and create lists of confirmed and possible time capsule locations at their institutions. For each, they should include the building, location, and any information about the materials used to create the capsule and its 
possible contents. A facility can create a list of departments, businesses, media, and other related contacts who can help in the recovery and access of a capsule. With a bit of planning, even the smallest of repositories can be ready when the call about a time capsule's discovery arrives.

\section{Returning to the Community}

April and May of 2016 were two incredibly busy months for the Rayfield Archives. The discovery of the time capsules not only captured the attention of local community members, it also reminded them of their connections to the university while making them aware of the work at the Rayfield Archives. During this time, many locals who wanted to see the materials in person or to relate stories of their connections to the capsules contacted the Rayfield Archives. One community member, who had seen a recovered photograph on the local news, called the Rayfield Archives to say that her husband was in the photograph and she recalled the night the image was taken as well as its placement in the capsule. These interpersonal connections change the time capsule collections from documentary evidence to carriers of cultural and material memory. As a participant in the creation of the time capsule, the woman who wanted to convey information about the photograph has an emotional connection to the capsule's materials. Most capsule creators expect the containers to be opened after their deaths. Creators who live to witness their time capsules' openings relive and remember the events the materials capture. Choosing to include a photograph of her then-boyfriend (later, husband) into a capsule placed in a location that meant so much created for her a strong emotional investment in the materials. Hugh Taylor argues that archivists sometimes do not see the materials they care for as evidence of material culture, but rather as "reliable information in support of other material culture." ${ }^{29}$ Taylor further asserts that archives materials can be powerful motivators in the lives of those who fully embrace their context. In short, "they are an extension of ourselves." 30

This personal connection to our time capsule materials can help explain why university alumni and current students alike often request access to time capsule materials. Since their recovery and stabilization, the materials have been used in several campuswide events and exhibits. Exhibiting these materials is important, not only in connecting with those who lived that particular student experience but for those students who are unfamiliar with that generation's cultural history. Though one of the two time capsules sustained irreparable damage, it has proved to be a great way to start a conversation with exhibit visitors on the materials' cultural memory and the importance of preserving university materials. As Barbara Craig states, "New generations, with no personal recollection of events can only experience the past indirectly. Their 
understanding of it will be shaped by community traditions and memories, nourished largely, it seems, by a growing buffet of popular historical books, films, and television programs." 31

As the archival profession continues to find new and engaging ways to connect communities to archival materials, educators are looking for ways to bring archives into their lesson plans. For a project where students created their own time capsules, one middle school teacher in Ohio sought out the services of a local university repository to show her class "what artifacts are and how artifacts document a specific time period." ${ }^{32}$ At Clemson University, the school's centennial celebration was an opportunity for the Special Collections Department to lobby for a records manager and university archivist. In the years leading up to the centennial, Clemson's Special Collections Department staff knew they would not be able to handle the increased requests for materials on the university's history. The impending celebration not only launched the university archives but also provided increased opportunities for Special Collections to partner with multiple constituents throughout the planning and celebration festivities. Moreover, the unearthing of a time capsule in the campus's first building and the placing of a new capsule, "generated more public attention for Special Collections than any other centennial event." ${ }^{33}$

The University of Alabama also used the centennial celebration of a beloved campus building to open a time capsule and connect with alumni and fans of Alabama history. Recovered from Smith Hall in 2010, the time capsule included a treasure trove of materials such as photographs, ribbons, jewelry, and military regalia, among other items. ${ }^{34}$ The opening of the box, as well as the creation of a new time capsule, was written up for a joint publication between the university and the Alabama Department of Archives and History. The full-color articles, including reproductions of items recovered from the time capsule, give readers an in-depth look at a period in the university's history. This publication partnership offers a large audience the chance to experience the recovered time capsule up close. Alumni stories, photographs and plans of a historic university, and an image of a new time capsule connect readers far beyond Tuscaloosa to the university. ${ }^{35}$

However, with increased interest comes an increase in the need for staff who can provide access to the materials. Clemson's Special Collections staff knew they would not be able to provide access to university archives materials in the years leading up to their centennial celebration. With grant funding, they were able to launch their university archives with staff dedicated to the task of processing backlogged collections, acquiring new materials, and working with multiple partners on centennial celebration activities. Not all institutions can devote the time or staff resources necessary to provide access to unique collections like time capsules at special events or in exhibits. At Illinois State University, displaying materials and providing access through educational tours, campus events, and 
special exhibits is an expected service of the Rayfield Archives to the campus and is financially and administratively supported by our library. Institutions that may not have our kind of administrative support for exhibiting may be able to find support through partnerships with local libraries, museums, or historical societies. University archives' connections with their institutions' alumni organizations, student newspapers, and other campus, local, and state publications can be an easy way to spread the word about time capsule discoveries. Tamar G. Chute suggests an "Ask an Archivist" article, where the archivist can "answer short questions from alumni while at the same time highlighting something within the collections." ${ }^{36}$ Making time capsule materials available to students, faculty, and campus affinity groups for research and special campus events like homecoming or first-year orientation can also help the archives make institutional connections while providing access to these unique collections. ${ }^{37}$

\section{Conclusion}

Whether through minor upgrades or significant construction, academic institutions are always changing to fit the needs of their student populations. Those changes can lead to surprising historical discoveries that often call upon the services of the university archives. The discovery of the time capsules at Illinois State University in 2016 provided the Dr. Jo Ann Rayfield Archives with the opportunity not only to strengthen ties with campus units such as Facilities and University Marketing and Communication, but also to open a conversation with the campus and the local community about collecting and preserving the university's history. It is essential for the Rayfield Archives to continue to collect these time capsules as objects of collective memory and for the artifacts they contain to more fully document the cultural history of the community we are both a part of and serve. In our retention of the materials from these time capsules, we should remember that they represent a specific group in our community (students) that can be difficult to document from all collective viewpoints. When we publicly display our time capsules, we introduce a collective memory to a new generation with no other direct connection to the history. While time capsules are an important addition to the overall collective memory, we must remember that they could be silencing other community voices. We must also remember community members' emotional ties to these objects and how their identities connect with both the time capsules and the buildings that once housed them. Though institutions with limited resources may find it difficult to work with time capsules, partnerships with campus entities and other local historical institutions may help bring these unique collections into the public eye, thus fostering new community connections and helping to build ther community's ever-growing collective memory. 


\section{Appendix A: Dr. Jo Ann Rayfield Archives Protocols for Found Time Capsules}

\section{Triage the Box}

The box must be documented before any other work is done. This information will help prepare staff for opening the box and for communicating with other campus units.

1. Start a document indicating where/when/how the capsule was discovered. Indicate who was called at the time of the capsule's discovery and how long it took to reach Archives.

2. Refer to the Known Time Capsule list; is this capsule on our list? If so, refer to research notes. If not, note the new capsule on the list and obtain background information.

3. Take notes on the appearance of the box. Include if the top was welded (indicating the type of tool needed to open the box), the type of metal used for the box, and any etchings found on the outside of the box.

4. Carefully shift the box around-did anything move?

a. Yes-this likely means the materials were not compromised by water or other elements. However, this does not mean the materials do not contain a contaminant. Have a disaster kit ready during the capsule's opening.

b. No-due to a failed seal in the lid or construction of the box, materials are likely compromised by water or other contaminants. Prepare for water-damaged materials, mold, and loss of time capsule objects.

\section{Contact Preservation in Milner Library}

1. Give Preservation the information you have gathered.

2. If you suspect the materials are compromised, work with Preservation to gather supplies needed for material extraction. Compromised materials SHOULD BE HANDLED as a disaster event, and disaster protocols followed. All items can be found in a Disaster Kit either in Milner Library or the supplies cabinet at the Rayfield Archives. These items include:

Tarps or plastic sheeting

Plastic aprons

Nitrile gloves

HEPA masks

Emergency mold abate-

ment kit (Preservation

should have this; tools and

supplies are also in the

stacks supply cabinet)

Paper towels
Plastic bags

Black marker for labeling

bags, other non-archival items

Post-it notes (for labeling groups of materials)

Notepad and pencils/laptop for taking notes

Camera for documenting the materials 
3. If you suspect the materials are adequate for opening in front of a camera or other media, proceed accordingly. HOWEVER, have a disaster kit nearby.

4. Identify a well-ventilated area for opening the time capsule. REMEMBER: Facilities will likely need to use a metal cutting tool to open the lid.

5. Lay out plastic sheeting beneath the time capsule BEFORE opening to catch metal shavings and any unexpected materials.

\section{Contact University Communications \& Marketing (UMC) and Facilities}

1. (Updated Fall 2018): Contact Milner Library’s Director of Communication and Outreach. Inform them of the time capsule, your current assessment of the capsule's contents, and whether you think it is viable for a live video opening.

2. Contact the Associate Director for Facilities Management. Inform them of the time capsule, the type of metal/material the box is made of (including how it was closed, i.e., type of weld, cement, glue, etc.), and the current plans by UMC for a live video opening.

3. Coordinate with UMC and Facilities for a joint opening of the time capsule.

\section{Opening the Box}

1. If the box appears safe to open on camera:

a. It is strongly recommended to open the box BEFORE cameras capture the "opening" of the box.

b. Conduct a cursory look at the materials. If they are safe to remove without causing damage to the materials or affecting the health of others in the area, filming and other media activities may commence.

2. If after opening the lid and the materials appeared to be compromised ... a. Discuss with UMC and Preservation whether filming should continue. If the materials are too compromised to continue, work with the box according to established disaster protocols.

3. Inventory the materials, indicating their condition and immediate preservation needs.

4. Photograph materials as they are inventoried (if materials need to be discarded due to damage, this will serve as the visual representation of that object).

5. Store materials in acid-free folders and boxes in a well-ventilated area with easy access for staff.

6. Once media requests have settled, the University Archivist will direct next steps for processing. 


\section{Notes}

1 Merriam Webster, s.v. "time capsule," https://www.merriam-webster.com/dictionary/time\%20 capsule.

2 Nick Yablon, "Encapsulating the Present Material Decay, Labor Unrest, and the Prehistory of the Time Capsule, 1876-1914," Winterthur Portfolio 45, no. 1 (2011): 4, http:// doi.org/10.1086/658932.

3 William E. Jarvis, Time Capsules: A Cultural History (Jefferson, NC: McFarland \& Co., 2003), 52.

4 Will Jarvis, "Time Capsule Secrets," interview by Stewart Brand, The Long Now Foundation, Seminars about Long-term Thinking, May 13, 2005, http://longnow.org/seminars/02005/may/13/ time-capsule-behavior.

5 “Crypt of Civilization,” Oglethorpe University, https://crypt.oglethorpe.edu/inventory.

6 Randall C. Jimerson, Archives Power (Chicago: Society of American Archivists, 2009), 192.

7 Jimerson, Archives Power, 202.

8 Maurice Halbwachs, The Collective Memory, trans. Francis J. Ditter Jr. and Vida Yazdi Ditter (New York: Harper \& Row, 1980), 25-26.

9 Halbwachs, The Collective Memory, 31.

${ }^{10}$ Halbwachs, The Collective Memory, 48.

${ }^{11}$ Halbwachs, The Collective Memory, 77.

${ }^{12}$ Halbwachs, The Collective Memory, 84.

${ }^{13}$ Kenneth E. Foote, “To Remember and Forget: Archives, Memory, and Culture," American Archivist 53, no. 3, (1990): 378-92, https://doi.org/10.17723/aarc.53.3.d87u013444j3g6r2.

${ }^{14}$ Barbara L. Craig, "Selected Themes in the Literature on Memory and Their Pertinence to Archives," American Archivist 65, no. 2 (2002): 279, https://doi.org/10.17723/aarc.65.2.362773030n128265.

${ }^{15}$ Craig, "Selected Themes," 276-89.

${ }^{16}$ Helen Willa Samuels, Varsity Letters: Documenting Modern Colleges and Universities (Chicago: Society of American Archivists, 1992), 75.

17 Samuels, Varsity Letters, 98.

${ }^{18}$ Jessica L. Wagner, “The Student as Subaltern: Reconsidering the Role of Student Life Material Collections at North American Universities," Archival Issues 35, no. 1 (2013): 38.

${ }^{19}$ Richard H. Kohn, "History and the Culture Wars: The Case of the Smithsonian Institution's Enola Gay Exhibition,” Journal of American History 82, no. 3 (1995): 1036-63, https://doi.org/10.2307/2945111. See also Elizabeth Yakel, "Museums, Management, Media, and Memory: Lessons from the Enola Gay Exhibition,” Libraries \& Culture 35, no. 2 (2000): 278-310.

${ }^{20}$ Dolores Hayden, The Power of Place (Cambridge, MA: MIT Press, 1995), 9.

${ }^{21}$ Hayden, The Power of Place, 16.

${ }^{22}$ The Dr. Jo Ann Rayfield Archives is the official repository for Illinois State University. The repository is named for its former repository head and Illinois State University history professor, Dr. Jo Ann Rayfield.

${ }^{23}$ Illinois State University, "We've discovered a SECOND time capsule at the South Campus demolition this morning," Facebook, April 19, 2016, https://www.facebook.com/IllinoisStateUniversity/ videos/10153570727752444.

24 “Time Capsules," Smithsonian Institution, Museum Conservation Institute, https://www.si.edu/ mci/english/learn_more/taking_care/timecaps.html.

${ }^{25}$ Robert L. Barclay, Time Capsules (Ottawa: Canadian Conservation Institute, Notes 1/6, 1995), 2 , https://www.canada.ca/content/dam/cci-icc/documents/services/conservation-preservationpublications/canadian-conservation-institute-notes/1-6-eng.pdf.

${ }^{26}$ Barclay, Time Capsules, 2.

${ }^{27}$ Patricia A. Morris, Time Capsules Old and New (South Carolina: South Carolina Department of Archives and History, 2003), 1, https://dc.statelibrary.sc.gov/bitstream/handle/10827/6993/DAH_ Time_Capsules_Old_and_New_2003.pdf. 
${ }^{28}$ Helen Fraser, The Time Capsule: Repository of the Past or Romantic Notion? (Nashville: American Association for State and Local History, Leaflet \#182, 1992), 3, https://learn.aaslh.org/products/ technical-leaflet-182-the-time-capsule-repository-of-the-past-or-romantic-notion\#tab-product_ tab_contents__1.

${ }^{29}$ Hugh Taylor, “'Heritage' Revisited: Documents as Artifacts in the Context of Museums and Material Culture,” Archivaria 40 (Fall 1995): 9.

${ }^{30}$ Taylor, “'Heritage’ Revisited,” 9.

${ }^{31}$ Craig, "Selected Themes," 279.

${ }^{32}$ Tamar Chute, Ellen Swain, and Sammie L. Morris, "Module 11-Connecting Students and Primary Sources: Cases and Examples," in Teaching with Primary Sources, ed. Christopher J. Prom and Lisa Janicke Hinchliffe (Chicago: Society of American Archivists, 2017), 148-49.

${ }^{33}$ Michael F. Kohl, "It Only Happens Once Every Hundred Years: Making the Most of the Centennial Opportunity,” American Archivist 54, no. 3 (1991): 395, https://doi.org/10.17723/ aarc.54.3.b142w775054w060j.

${ }^{34}$ John Hall, “Capsule in a Cornerstone: The Treasure of Smith Hall,” Alabama Heritage no. 98 (Fall 2010): 19-24.

${ }^{35}$ Matthew H. Kelley, “Building a Time Machine," Alabama Heritage no. 98 (Fall 2010): 25.

${ }^{36}$ Tamar G. Chute, "Perspectives on Outreach at College and University Archives," in College and University Archives: Readings in Theory and Practice, ed. Christopher J. Prom and Ellen D. Swain (Chicago: Society of American Archivists, 2008), 142.

${ }^{37}$ Chute, "Perspectives on Outreach," 141-45. Chute cites a number of outreach activities for academic archives in her chapter, including department-made publications, tours, and oral histories, as well as the aforementioned suggestions of alumni outreach, research, and presentation at special events.

\section{ABOUT THE AUTHOR}

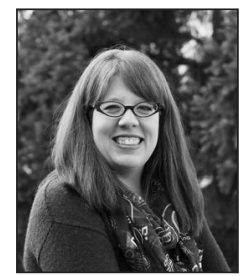

April Karlene Anderson-Zorn is the university archivist for Illinois State University. Anderson-Zorn earned master's degrees in library and information science from Florida State University and in history from the University of Central Florida. She is a certified archivist through the Academy of Certified Archivists and holds a Digital Archives Specialist Certificate through the Society of American Archivists. Anderson-Zorn has also worked as an archives consultant partnering with a number of academic institutions and companies to help set up their archives programs. 